\title{
Bridging the Gap Between Service-Oriented and Object-Oriented Architectures in Information Systems Development
}

\author{
Viera Rozinajová, Marek Braun, Pavol Návrat and Mária Bieliková \\ Slovak University of Technology, SK
}

\begin{abstract}
The most popular development methodologies in the last decade are based on object-oriented techniques. The goal of this paper is to investigate the possibilities of extending the object-oriented methodology of information systems development with a service-oriented approach and to examine the benefits of this extension. We propose an augmentation to an object-oriented methodology known as BORM that incorporates service-oriented techniques. To demonstrate the advantages of this combination, the extended methodology was applied and its features evaluated.
\end{abstract}

Keywords: Service Oriented Architecture, Business Process Modeling, Business Process Execution Language, Object-Oriented Methodology

\section{Introduction}

Service oriented architecture (SOA) is one of the most challenging concepts in information systems development. Indeed, there are reasons to believe that it brings flexibility, scalability and faster system development. Current information systems are not developed for quick and dynamic modifications. Changes in processes that can have an impact on the entire organization are often reflected in information systems that require long time horizons to modify. If the organization wants these changes, it must wait a long time for the modification.

In contrast, SOA systems consist of modular components with standardized interfaces through which components (services) deliver their functionality. To set up

Institute of Informatics and Software Engineering

Faculty of Informatics and Information Technologies

Slovak University of Technology, Ilkovicova 3, 84216 Bratislava, Slovakia

\{rozinajova, navrat, bielik\}@fiit.stuba.sk

Please use the following format when citing this chapter:

Rozinajová, V., Braun, M., Návrat, P. and Bieliková, M., 2008, in IFIP International Federation for Information Processing, Volume 274; Advances in Information Systems Research, Education and Practice; David Avison, George M. Kasper, Barbara Pernici, Isabel Ramos, Dewald Roode; (Boston: Springer), pp. $125-134$. 
SOA, it is often necessary to concentrate on business processes, their modeling and management. According to Erl (2008), many of the services that will eventually be modeled and designed will be business services, responsible for accurately encapsulating and expressing business logic. Therefore, a comprehensive set of business models and specifications is needed. In this paper we focus our attention on the systems based on the business process-oriented approach to SOA, i.e. the systems consisting of the services that support business process realization.

These services express business logic as abstract representations of business capabilities that the business can compose into processes. Therefore, a well defined business process is a critical success factor for deploying SOA, and using a methodology based on business process modeling would be beneficial for systems reflecting business needs. This is one of the reasons why we have chosen BORM methodology (Business Object Relation Modeling) (Knott et al. 2000) - an objectoriented methodology for information system design and development based on the business process modeling. BORM itself focuses to modules from a reusability point of view and its focus is also to business process modeling. These aspects are similar to SOA principles, but BORM is pure object-oriented.

\section{BORM methodology}

BORM, Business Object Relation Modeling, was originally developed in 1993 and was intended to provide seamless support for building object-oriented software systems based on pure object-oriented languages and environments such as Smalltalk and object databases. Subsequently, it has been realized that this method has also significant potential in business process modeling and other related business and user requirements issues.

Business Object Relation Modeling is an approach to both process modeling and the subsequent development of information systems. It provides a methodology that facilitates the description of how real business systems evolve, change and behave. It has been used successfully for developing a number of information systems in various areas of business activities. The BORM approach is based on each object having three independent attributes called dimensions. These dimensions are data, behavior, and history (a composition of states and transitions, i.e. the object lifecycle).

BORM is fundamentally an object-oriented development methodology, but differs from other such methodologies. In BORM, the extent of knowledge required to understand an object and use it effectively in the design process evolves throughout the development process in a clear, precise and consistent manner. Initially, objects are defined as business objects, where only knowledge of their activities, relationships, and intercommunications is required (Satzinger and Orvik 1996). Business objects during the design process are changed via a set of clearly defined and consistent techniques into conceptual objects. During the implementa- 
tion phase, conceptual objects evolve in a similar structured and controlled manner into software objects. Thus at each stage of the development process, BORM requires some degree of knowledge about the object to proceed further.

Contrary to some other object-oriented methodologies, which start with a set of initial objects without providing any method for discovering them, the BORM development methodology starts from an informal problem specification and provides both methods and techniques to enable this informal specification to be transformed into an initial set of interacting objects. The main technique used here is BORM is modified Object Behavioral Analysis (BOBA).

BORM, similar to other object-oriented development methodologies, is based on the spiral model of the development life cycle (Boehm 1981). One loop of the object-oriented spiral model contains stages of strategic analysis, initial analysis (both work with business objects), advance analysis, initial design (conceptual objects), advanced design, implementation and testing (software objects):

1. The first three stages are collectively referred to as the expansion stages. Expansion ends with finalizing the detailed analysis, which fully describes the solution of the problem from the requirements point of view.

2. The remaining stages are called consolidation stages. These are concerned with the process of developing from 'expanded ideas' to a working application. During these stages, the conceptual model is step by step transformed into a software design.

\section{Extending BORM with SOA}

Our goal was to examine if the object models created using BORM development can be utilized to support the design of service-oriented systems and to investigate under which conditions this procedure will work.

For the purpose of practical investigation, an experimental project from the domain of self-service DVD rental store was developed. This project consisted of three phases. In the first step, design via original BORM was performed. In the second step, the design using SOA principles was developed. And in the last step, consolidation of these two designs was completed.

BORM design was performed according to its six stages. The SOA design was built using SOA principles and Business Process Execution Language (BPEL). BPEL models were used for visualization of service orchestration. These models provide a complete view of service architecture.

Comparing BORM and BPEL showed a similarity in activities. BORM process models are comparable with UML activity and state diagrams whereas they combine both state and activity aspects of processes in a single diagram. Besides verti- 
cal relations they also capture horizontal ones, which describe communication among processes of various participants. The similarity between BORM and BPEL processes lies in identified services and in process mapping where the services are orchestrated in related way - in terms of nesting, cycling, branching, and so on. The differences between models are due to their special purpose. BORM models are created in the first stages of system development in order to describe the problem area whilst BPEL models are designed in the latter phases based on well-known user needs and expectations. But BORM's process models are a good foundation for building SOA and BPEL models, if the latter are desired. More generally, when comparing BORM and SOA, it was found that support of services identification as functional elements (for SOA) together with their forming into cooperative unit is absent in BORM. The cooperative unit of formed and also orchestrated services is called a "process layer" in this paper. It is necessary to realize that there is a difference between the process layer on one hand and a business layer, business process and process diagram/model on the other. They are considered as two different models.

The gap between BORM and SOA should be filled. BORM methodology does not provide all the necessary information. Some additional data must be added for recognition of relevant activities as services. Moreover, their classification and grouping should be performed. Into the original BORM's six phases the additional activities were added taking into account the nature of each phase as well as its overall purpose in the methodology.

First and second phase. The aim of the first two phases of BORM is to describe a problem area. The requirements of the future system are defined along with process diagrams. These phases include all the necessary activities - also for SOA. Hence an upgrading of these phases is not required. In relation to the experimental project, project objectives were defined, together with sets of required system functions and system scenarios. And also the business processes for operators (customer administration + movie administration) and customers (movie rent and return, movie reservation and canceling of reservation) were recognized.

Third phase. In the third phase, process diagrams are processed and information for an initial software specification is extracted. The following activities were added to this phase in order to support SOA: initial service identification (based on process models), their classification - grouping according to their logic and decomposition of services, if it is appropriate. In this phase of the system design, object diagram and class diagram with relationships between objects, resp. classes has been created together with its extension by objects' dynamic properties. To support the SOA approach, initial identification and classification of services based on business processes was completed. Example of business services for customer is shown in Table 1. 
Table 1 Initial list of customer business services

\begin{tabular}{l|l}
\hline Participant & Business services \\
\hline Customer & $\begin{array}{l}\text { person's identification and authentication } \\
\text { person's log off } \\
\text { administration of borrowings } \\
\text { creation of list of rented movies } \\
\text { creation of list of reserved movies } \\
\text { finding a movie } \\
\text { movie reservation } \\
\text { canceling of movie reservation } \\
\text { stock out of movies reserved on current branch store } \\
\end{array} \begin{array}{l}\text { (in case of picking up the movies) } \\
\text { receiving of movie (in case of returning borrowed movie) }\end{array}$ \\
\hline
\end{tabular}

Fourth phase. Design in the fourth phase proceeds to software implementation. The relationships among objects are improved and transformed. Design patterns are applied and reusable components identified. From an SOA point of view, the existing services are identified and the input and output parameters are specified.

Business services are considered as SOA operations and bundled into SOA services according to theirs functionality. In this phase analysts should consult with developers to identify services from an implementation point of view. This is important to ensure effective implementation (it should be appropriate for decomposition, consolidation, regrouping of services etc.). Outputs of this phase are object diagrams enriched by design patterns and a list of regrouped SOA operations bundled in services. An example of customer service with its operations is shown in Table 2 .

Table 2 List of SOA services and theirs operations for customer service with input and output parameters

\begin{tabular}{|l|l|l|l|}
\hline Service & Operation & $\begin{array}{l}\text { Input } \\
\text { parameters }\end{array}$ & $\begin{array}{l}\text { Output } \\
\text { parameters }\end{array}$ \\
\hline Customer & $\begin{array}{l}\text { person's identification } \\
\text { and authentication }\end{array}$ & $\begin{array}{l}\text { customer id, } \\
\text { branch store id }\end{array}$ & $\begin{array}{l}1-\text { successful } \\
0-\text { unsuccessful }\end{array}$ \\
\cline { 2 - 4 } person's logging off & customer id & $\begin{array}{l}1-\text { logging off } \\
\text { successful } \\
0-\text { logging off un- } \\
\text { successful }\end{array}$ \\
\cline { 2 - 4 } & $\begin{array}{l}\text { registration of new cus- } \\
\text { tomer }\end{array}$ & name, address & $\begin{array}{c}1-\text { registration suc- } \\
\text { cessful } \\
\text { - registration un- } \\
\text { successful }\end{array}$ \\
\hline
\end{tabular}




\begin{tabular}{|l|l|l|l|}
\hline Service & Operation & $\begin{array}{l}\text { Input } \\
\text { parameters }\end{array}$ & $\begin{array}{l}\text { Output } \\
\text { parameters }\end{array}$ \\
\hline \multirow{7}{*}{$\begin{array}{l}\text { canceling of customer } \\
\text { registration }\end{array}$} & customer id & $\begin{array}{c}1-\text { canceling suc- } \\
\text { cessful } \\
0-\text { canceling unsuc- } \\
\text { cessful }\end{array}$ \\
\cline { 2 - 4 } & $\begin{array}{l}\text { person's identification } \\
\text { via identification card }\end{array}$ & card id & $\begin{array}{l}\text { customer id and } \\
\text { name }\end{array}$ \\
\cline { 2 - 5 } & $\begin{array}{l}\text { modification of cus- } \\
\text { tomer data }\end{array}$ & $\begin{array}{l}\text { customer id, } \\
\text { new data }\end{array}$ & $\begin{array}{l}\text { - data modification } \\
\text { successful } \\
0-\text { data modification } \\
\text { unsuccessful }\end{array}$ \\
\cline { 2 - 4 } & listing of customers & - & $\begin{array}{l}\text { list of customers } \\
\text { with their data }\end{array}$ \\
\hline
\end{tabular}

Fifth phase. In the fifth phase a transformation of conceptual objects closer to the concrete implementation environment is made. Besides adjusting the class and object diagrams, process models of services are prepared in order to form a process layer of implementation. Design of the process layer where services and relations among them are captured, is made for later implementation purposes. This produces an outline for implementation of previously orchestrated services. The process diagrams from the second phase are helpful in this phase and the process layer design can be based on them.

The process layer can be designed using workflow patterns, business process modeling notation (BPMN), or eventually BPEL. BPEL should be used in this phase to create a high level design of the process layer, in case the process layer is later implemented in this language.

In the experimental project the diagrams of software objects capturing a server side with relation database were created. Then a process layer was designed (see Fig. 1) using NetBeans BPEL notation.

Sixth phase. In the sixth and final phase, the physical implementation of the system including implementation of identified services using web service standards was performed. The process layer, which is used for services interconnection is also created.

A prototype of a self-service DVD rental store was implemented in Java with MySQL. The Java application consisted of the web service layer, in which single SOA operations was implemented, and of the process layer, which was bundled with a user interface implemented using Java Server Faces and MySQL database. Implementing the process layer using BPEL offers a flexible and scalable system as SOA asserts. 


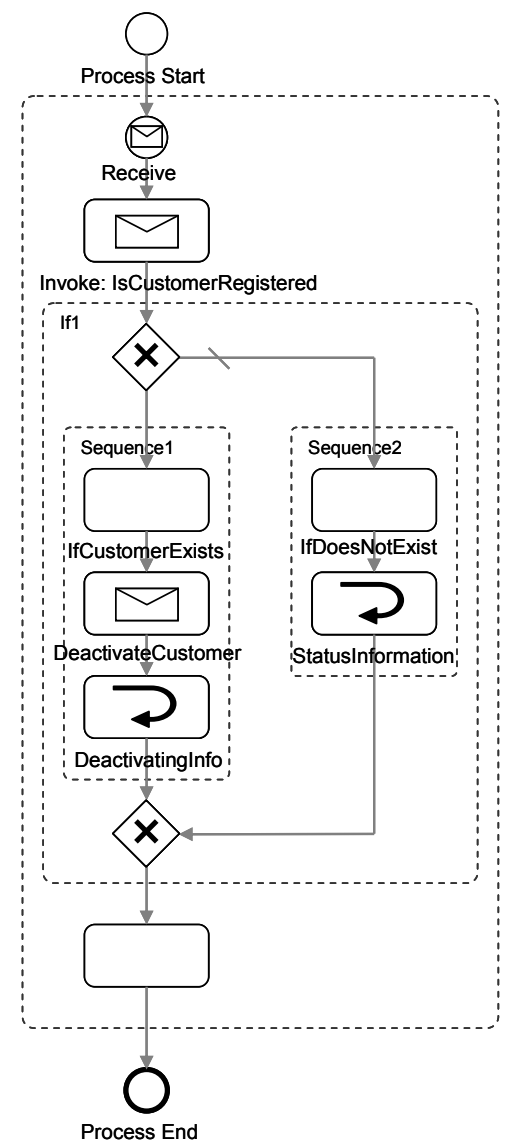

Fig. 1 Design of a process for customer deactivation

Our experiment has demonstrated that if the development of information systems according to BORM methodology is performed thoroughly, we can take advantage of the created models of business processes to support the system design while respecting the service oriented approach. Moreover, in addition to the benefits of models of business processes, the extended diagrams of objects and classes together with their relationships and dynamic properties from the BORM development can be beneficial when utilized in the process of service-oriented systems development.

An overall life cycle of extended BORM methodology is shown in Fig. 2 (BORM methodology is depicted with inspiration from (Molhanec 2008). 


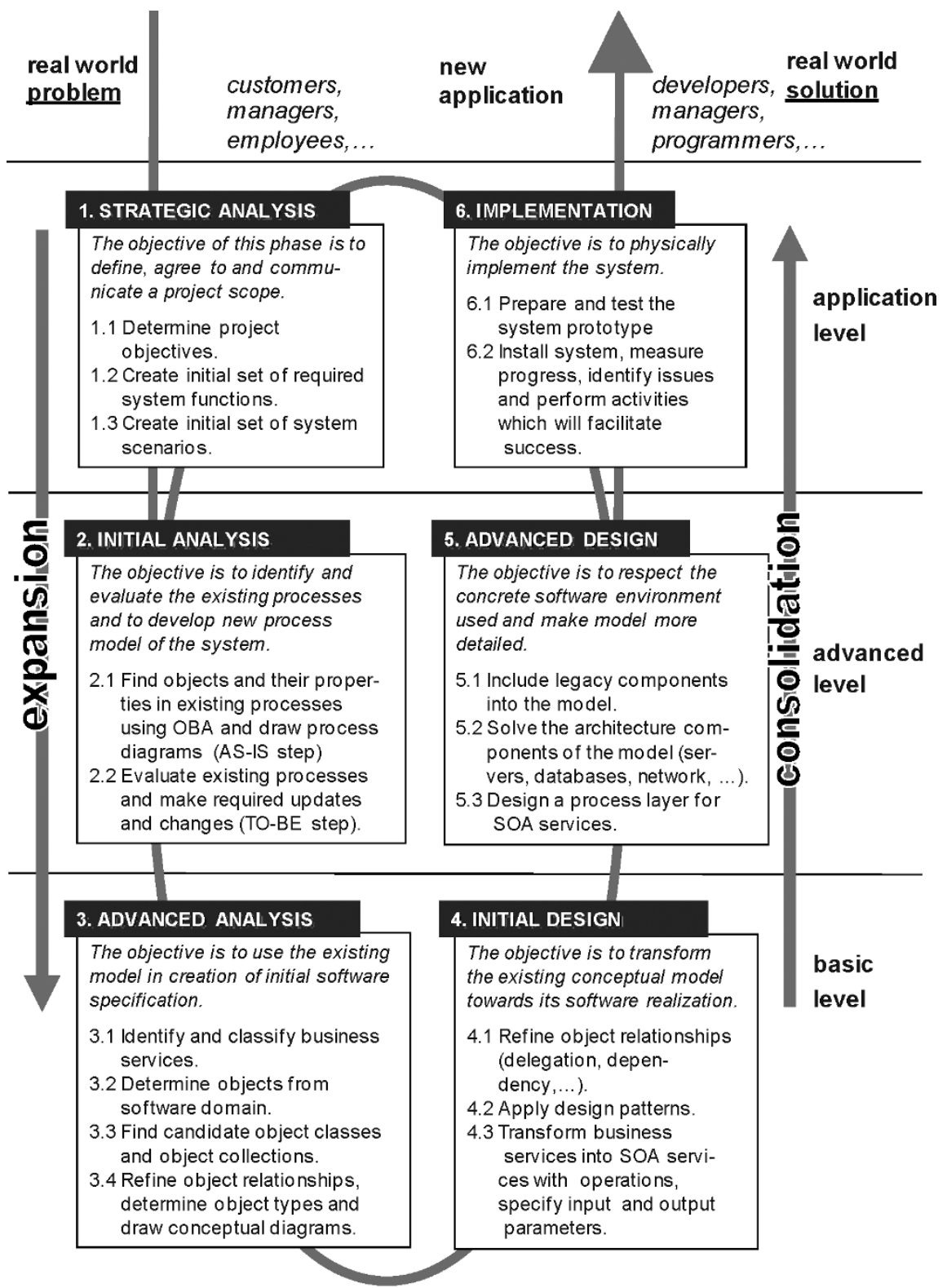

Fig. 2 Life cycle of extended BORM methodology 


\section{Conclusions}

This paper investigated the possibilities of extending the BORM methodology by incorporating the SOA approach. The development following all the steps of the original BORM sequence, augmented by activities allowing SOA principles to be a part of the design has shown to be viable - thus taking a step towards a new methodology for information system design and development.

We observed that good, quality design is possible using the BORM process models for initial service identification and the process layer implementation according to service oriented architecture. It is also possible to make use of other BORM diagrams from initial steps of system analysis and design. As a result of BORM extension, an adapted methodology with extended phases of the life cycle was created. This methodology is based on object-oriented approach taking into account requirements needed for service oriented principles. The extension is effective in the last four phases of the original BORM methodology. The new upgraded methodology allows smooth design of information systems, facilitating the building of systems that are service-oriented. An implementation of system prototype via extended BORM methodology served to evaluate the proposed extensions.

By extending the original BORM methodology with SOA, we achieve a methodology that enables identification and implementation of an information system process layer. The realization of the process layer can be done in several ways. If we choose BPEL, these changes can be performed at BPEL process model level using the BPEL engine. Thus we have the possibility of making fast and flexible modifications to information systems according to actual needs, and with flexibility among the most desirable attributes of information systems today, this is a step toward development of improved methodologies.

Acknowledgements This work was partially supported by the Slovak Research and Development Agency under the contracts No. APVV-0391-06 and No. APVT-20-007104.

\section{References}

1. Bell M.(2008). Service-Oriented Modeling (SOA): Service Analysis, Design, and Architecture. John Wiley \& Sons, New Jersey.

2. Erl, T. (2008). SOA: Principles of service design. Prentice-Hall, Boston

3. Juric M., Mathew B., Poornachandra S. (2006). Business Process Execution Language for Web Services, Packt Publishing, Birmingham, UK

4. Knott R. P., Merunka V., Polak J. (2003). The BORM methodology: a third-generation fully object-oriented methodology. Knowledge Based Systems, 16 (2): 77-89. 
5. Molhanec, M. (2004). An overview of Information Modelling for Manufacturing Systems In: 27th Int. Spring Seminar on Electronics Technology ISSE 2004. Sofia: IEEE, 2004, vol. 1, pp. 36-41.

6. Polášek,I., Chudá, D., Kristová, G. (2006). System dynamics modeling in the new version of UML 2.0 language. In: System Integration 2006, Žilina, University of Žilina, pp.311-317.

7. Satzinger J. W., Orvik T.U. (1996). The Object-Oriented Approach-Concepts, Modeling and System Development, Boyd\&Fraser. 